\title{
Measuring Numeracy in a Community College Context: Assessing the Reliability of the Subjective Numeracy Scale
}

Kate S. Wolfe

Hostos Community College CUNY, kwolfe@hostos.cuny.edu

Sarah L. Hoiland

Hostos Community College CUNY, shoiland@hostos.cuny.edu

Follow this and additional works at: https://digitalcommons.usf.edu/numeracy

Part of the Quantitative Psychology Commons, and the Quantitative, Qualitative, Comparative, and Historical Methodologies Commons

\section{Recommended Citation}

Wolfe, Kate S., and Sarah L. Hoiland. "Measuring Numeracy in a Community College Context: Assessing the Reliability of the Subjective Numeracy Scale." Numeracy 10, Iss. 2 (2017): Article 6. DOI: http://doi.org/ 10.5038/1936-4660.10.2.6 


\title{
Measuring Numeracy in a Community College Context: Assessing the Reliability of the Subjective Numeracy Scale
}

\begin{abstract}
In this paper, our goals were to assess the suitability of the Subjective Numeracy Scale (SNS), developed for health-care use, in a new context with predominantly minority students at a South Bronx community college and to identify any race/ ethnicity, gender, and ESL enrollment effects. The scale assesses perceptions of quantitative reasoning skills and preferences for data presentation. This scale was given to a convenience sample of students in behavioral sciences classes. Results show that the SNS scale was reliable with our sample using the full thirteen-question scale or the shorter eight-item version. Gender, race/ ethnicity, and English as a Second Language (ESL) are related to perceptions of QR/QL. This study may help researchers see the SNS as a reliable instrument across samples and as a way to measure numeracy. The results of the multivariate analyses raise questions for future research about cultural differences for numerical presentation among these ethnic groups and our international student population.
\end{abstract}

\section{Keywords}

numeracy assessment, reliability, subjective numeracy scale, community college, numeracy

\section{Creative Commons License}

\section{c) (7) (8)}

This work is licensed under a Creative Commons Attribution-Noncommercial 4.0 License

\section{Cover Page Footnote}

Kate Wolfe, Ph. D., is an assistant professor of psychology at Hostos Community College, CUNY. Along with co-author Sarah Hoiland, she has worked on several research projects at Hostos related to student perceptions of online learning and student perceptions of quantitative literacy and quantitative reasoning. Her other area of interest is urban college student attitudes toward sexual minorities, specifically examining the relationship of dichotomous thinking, along with traditional correlates to sexual and gender prejudice. Currently, she is a faculty associate on a collaborative National Science Foundation project titled "NICE: Numeracy Infusion for College Educators" with co-PIs Esther Wilder, Professor of Sociology at Lehman College, and co-author Sarah Hoiland.

Sarah L. Hoiland, Ph.D., is an assistant professor of sociology at Hostos Community College. She has worked with co-author Kate Wolfe on several research projects at Hostos related to student perceptions of online learning and student perceptions of quantitative literacy and quantitative reasoning. Her other area of interest is motorcycle club subculture and the historical and contemporary representations of females within the male-dominated subculture. Currently, she is a principal investigator $(\mathrm{PI})$ of a collaborative National Science Foundation project titled "NICE: Numeracy Infusion for College Educators" with co-PI Esther Wilder, Professor of Sociology, at Lehman College. 


\section{Introduction}

This study examines the reliability of the Subjective Numeracy Scale (SNS) in a particular new context - an urban, diverse community college. The SNS scale, like many other assessments of numeracy, was developed by the health numeracy research community to assess numeracy among patients. Vacher and Chavez (2009) provide a thorough literature review of this particular field and the resources developed for assessing numeracy, and they also highlight the health community's emphasis on finding ways to cope with innumeracy such as improving communication skills among medical professionals who are talking to innumerate patients.

The SNS was developed by Fagerlin et al. (2007) as a subjective assessment that could serve as an alternative to objective assessments of numeracy in part to combat the difficulties surrounding administering objective numeracy assessments on the Internet or on the phone. As Schwartz et al. (1997) and Lipkus, Samsa, and Rimer (2001) note, many people are averse to objective numeracy assessments. Fagerlin et al. (2007) conducted three studies to develop the SNS and, in one study (their "Study 3"), they selected fifty-two people in a university hospital cafeteria and randomly gave them either an objective numeracy assessment (the 11-item Lipkus, Samsa, and Rimer 2001 assessment) or the 13-item SNS; the participants who took the SNS had significantly lower rates of annoyance, stress, and frustration and significantly higher rates of enjoyment than those participants who took the objective assessment. In addition, the SNS took less time and participants were more willing to take another similar survey, and it is closely associated $(r=0.68)$ with the 11-item Lipkus-Samsa-Rimer objective assessment (Fagerlin et al. 2007). Zigmund-Fisher et al. (2007, 670) conclude, "It seems clear that the SNS significantly predicts the same behaviors as objective numeracy measures do."

At Hostos Community College, many of our students are averse to standardized objective tests for a variety of reasons including language barriers, previous experience with New York State Regent's exams (which are required to earn a high school diploma), and the City University of New York's (CUNY's) entrance exams. Because the SNS proved, in the health-care context, to be a reliable alternative to objective numeracy assessment, we thought it might be a good fit for community college students. Thus, the SNS seemed like it might be an ideal assessment tool to implement at Hostos Community College because of the reported ease in administrating it, the reduced stress reported by respondents, and the close association to objective assessments of numeracy.

Our goals in this study are to assess the suitability of the SNS, developed for health-care use, in a new context with predominantly minority students at a South Bronx community college, and to identify any correlations between the SNS score 
and race/ethnicity, gender, and English as a Second Language (ESL) enrollment. Exploratory factor analyses was conducted using all 13 SNS items as well as the smaller 8-item scale to determine if using this measure with our student population yields the same internal consistency as the original study. Indeed, our results are very similar to those in Fagerlin et al. (2007). We then examine how factors of race, ethnicity, gender, and ESL status affect the results within this urban, diverse community college. We believe that our findings show that the SNS proved reliable in this context and is a valuable tool for educators to assess student perceptions of numeracy in a non-threatening way.

\section{Numeracy and Community College Students}

\section{The National Context}

We use "numeracy" to refer to "the ability to understand and use numbers and data in everyday life" (Madison 2003, 3). The health numeracy research community has highlighted the detrimental effects of innumeracy-even to the point of life-or-death consequences. For example, jurors have been swayed by inaccurate probabilities presented in court by medical professionals, which resulted in a mother being convicted of murder. In that case, a doctor said that the statistical likelihood of two babies dying from "cot death" or Sudden Infant Death Syndrome (SIDS) was 1 in 73 million (Donnelly 2005). He arrived at this figure by squaring the likelihood of one baby dying from SIDS (approximately 1 in 8,500 ) and came up with 1 in 73,000,000. By ignoring potential genetic factors, the doctor made a seemingly open-and-shut statistical case against a mother who lost two children to SIDS.

Numeracy also impacts everyday quality of life and social mobility. For example, research finds that household income is positively correlated with numeracy (Kutner et al. 2007). Lusardi (2012) reports a connection between numeracy and financial decision-making, with numerate people more likely to plan for retirement. And Gerardi, Goette, and Meier (2010) conclude that buyers who display fewer numeracy skills are more likely to experience foreclosure or to be behind on their mortgage payments and were also disproportionately impacted by the sub-prime mortgage crisis.

While numeracy is important for all, research suggests that there are gender, ethnic, and socioeconomic disparities in numeracy assessment results and in changes in numeracy over time. For example, the elderly, those who are less educated, and minorities fare more poorly on numeracy assessments (Lusardi 2012). Moreover, the 2003 National Assessment on Adult Literacy showed males' average numeracy scores are higher than females' but that females have made significant gains and are narrowed the gap between 1992 and 2003 (Kutner et al. 2007). In both 1992 and 2003, Blacks were reported to have the lowest rates of 
numeracy proficiency (1\% and 2\% respectively) among all American racial/ethnic groups, but the group nevertheless made significant gains as the share scored as below basic proficiency fell from $57 \%$ to $47 \%$. By contrast, Hispanics, who were only marginally more likely to be rated as proficient, saw no significant growth in numeracy at any point on the proficiency spectrum (Kutner et al. 2007).

These correlations between numeracy and demographic markers are important to community college students, who are disproportionately minority, female, and living in poverty. It is hardly surprising given these demographic characteristics that community college students are particularly in need of numeracy gains. Thirty percent of today's community college students in the United States have "only basic quantitative literacy skills, meaning they are unable to estimate if their car has enough gasoline to get to the next gas station or calculate the total cost of ordering office supplies" (Atkinson, Czaja, and Brewster 2006, 1). As community college faculty at a Hispanic-Serving [twoyear] Institution with a fifty-year commitment to social and economic justice in the South Bronx, we see numeracy as a social justice issue related to increased life chances and social mobility for our students.

A dedicated group of scholars in higher education have been working on issues related to numeracy for nearly twenty years, and although the group was originally comprised of mathematicians, there are now leading scholars from many other fields. Steen wrote Achieving Quantitative Literacy: An Urgent Challenge for Higher Education in 2004, and ten years later Elrod wrote "Quantitative Reasoning: The Next 'Across the Curriculum' Movement" in 2014. Dingman and Madison $(2011,18)$ argue the core quantitative reasoning competencies (interpretation, representation, calculation, analysis and synthesis, assumptions, and communication) are "closely related competencies in all subjects." Some, like Sweet and Strand (2006, 1), have argued that "sociology is well positioned to be a leading discipline in the cultivation of students' abilities to interpret statistical information and put those interpretations to meaningful use." While the progress in the numeracy movement has been commendable, our work is impeded by a lack of data on students' numeracy in community colleges, specifically urban institutions with large Hispanic and Black student populations. To begin to mitigate this problem, this study explores the SNS' reliability in the community college context and examines how race and ethnicity, among other factors, affects students' perceptions of numeracy.

\section{Hostos Community College}

Hostos Community College is part of the City University of New York (CUNY) and is one of three CUNY schools in the Bronx. While the vast majority of Hostos students are low income (see Table 1), CUNY's Office of Institutional Research reports that $29 \%$ of those low-income students live in households that earn under 
$\$ 10,000$ per year. Of the 1,091 students entering in the Fall 2011 cohort, 1.4\% earned an associate's degree in two years, $12.6 \%$ in three years, and $19.8 \%$ in four years ("Graduation Profile," 2011). Mathematics is a major roadblock to student retention and graduation. Nearly $85 \%$ of our students do not pass the mathematics skills exam ("Student Profile," 2015), which is a failure rate nearly $20 \%$ more than the community college national average, and only $9 \%$ of Hostos students pass all three placement exams. In comparison, one-third of incoming community college students nationwide fail to meet their institution's standards for college readiness (Bailey 2009, 13). Hostos students who fail to pass the entrance exam must enroll in non-credit bearing remedial math classes and workshops until they pass, which can be extraordinarily frustrating for students and also negatively impact financial aid.

Table 1

Sociodemographic Characteristics of Students at Hostos vs. Average at Community Colleges

\begin{tabular}{llllll}
\hline & Minority & Hispanic & Female & Low Income & $\begin{array}{l}\text { First } \\
\text { Generation }\end{array}$ \\
\hline Hostos & $92 \%$ & $60 \%$ & $66 \%$ & $73 \%$ & $49 \%$ \\
Community College Average & $66 \%$ & $38 \%$ & $57 \%$ & $65 \%$ & $49 \%$ \\
\hline
\end{tabular}

Notes: Minority includes American Indian, Alaska Native, Black (not of Hispanic origin), and Hispanic. Low income refers to those with household incomes of less than $\$ 30,000$.

Sources: Office of Institutional Research and Student Assessment, Office of the President, Hostos Community College. 2015. Student Profiles. Last retrieved on Feb. 22, 2017. http://www.hostos.cuny.edu/oaa/oir/PublicDocuments/StudentProfile.pdf

Many of the students who graduate from Hostos transfer to a four-year CUNY institution. According to Wilder $(2009,168)$, "transfer students [to one CUNY four-year institution] from community colleges performed less well on the [quantitative skills] assessment tests" and were "less comfortable working with data." To address these deficiencies, it would seem extremely important for twoyear institutions to integrate numeracy across the curriculum.

Hostos has implemented several initiatives such as a QR/QL initiative across the curriculum and has institutional support to respond to Elrod's (2014) call for an "across the curriculum movement." The Hostos Center for Teaching and Learning houses graduate students who serve as Visiting QR/QL Fellows, who assist faculty in designing and implementing QR/QL assignments, hold workshops and training sessions, and help increase QR/QL awareness campuswide. These fellows come from various disciplines including sociology, musicology, and economics. They work with faculty in most non-STEM departments. In January of 2017, Hostos Community College and Lehman College were awarded a collaborative National Science Foundation (NSF) grant for the Numeracy Infusion for College Educators (NICE) Program. Principal Investigators (PIs) Hoiland (Hostos) and Wilder (Lehman) will provide professional development for twenty-four faculty members from across the disciplines at all three CUNY institutions in the Bronx in best practices for effective QR/QL pedagogy beginning in June 2017. 


\section{Methods}

Developing numeracy skills includes developing good habits of mind and the ability to apply complex thinking processes to numerical information in everyday life. Because few numeracy assessments have been conducted in the context within which we teach and because many of our students find such assessments to be stressful, we decided to use the SNS. This scale uses Likert-type responses for each question about cognitive abilities and preference for how numerical information is displayed. The individual SNS items are included Table 2 below. We used the original 13 items that Fagerlin et al. (2007) tested when developing their scale. The first four items measure beliefs about cognitive abilities and the remaining nine items measure preferences when presented with numerical information. We also compared the reliability of the 13-item and 8-item SNS versions presented in the Fagerlin et al. study.

Table 2.

Subjective Numeracy Scale Items

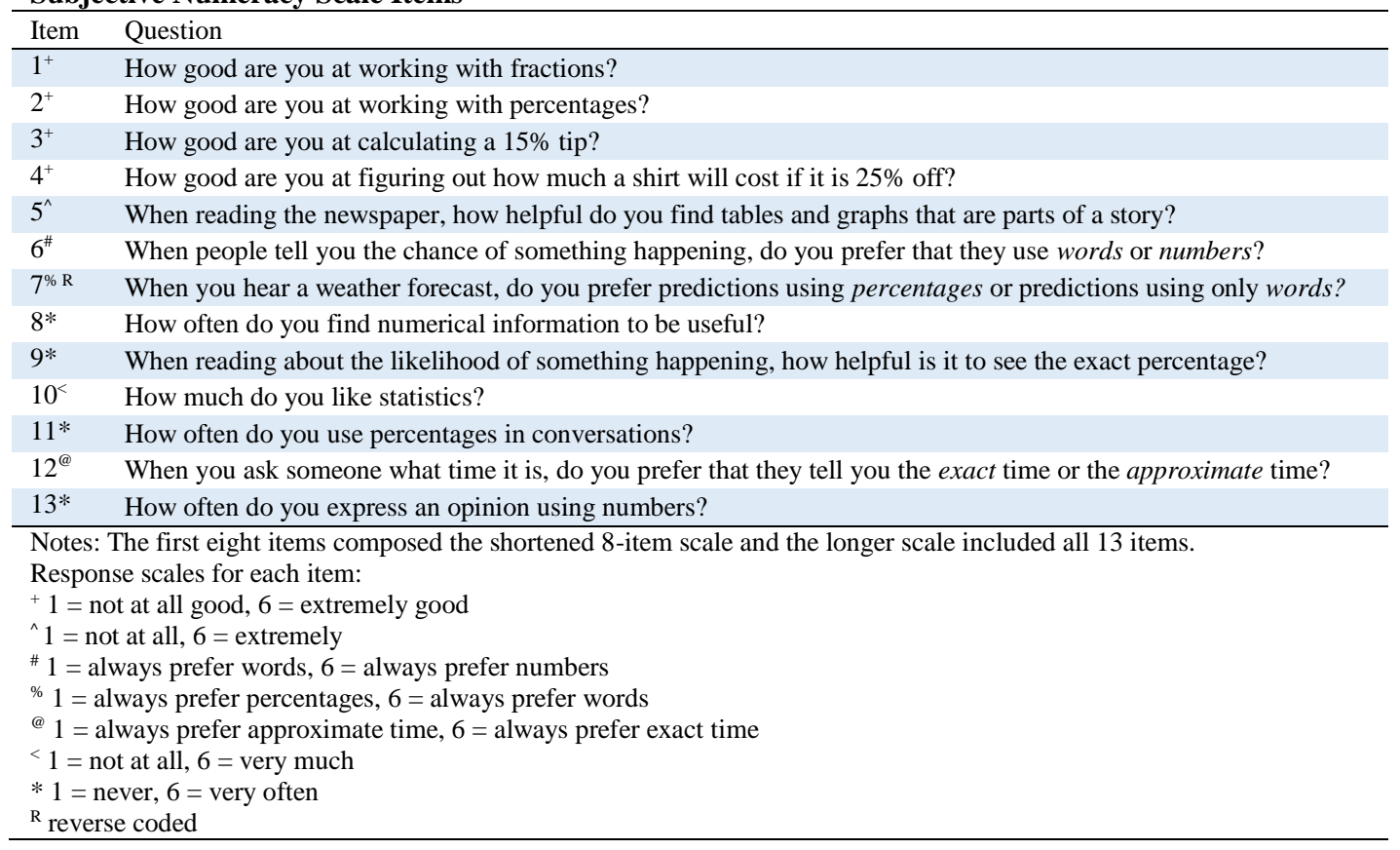

Research participants were students in the authors' classes. Student Research Assistants (SRAs), supported by Department of Education Title V funding, administered the surveys on iPads via a Google Forms survey in class. SRAs showed participants a folder on the iPad that included the SNS and a demographic questionnaire. Those who were absent that day were not allowed to participate so 
that all participants completed the SNS under the same circumstances. Surveys were completely anonymous and confidential. Our institution's Human Research Protection Program (HRPP) approved the study and certified SRAs.

\section{Respondents}

The sample was a convenience sample of students enrolled in the authors' courses (Anthropology 101: Introduction to Anthropology, Sociology 101: Introduction to Sociology, or Psychology 110: Lifespan Development) in spring 2015. Sociology 101 was linked to an ESL course, which skewed our demographics but also provided important information regarding students' perceptions among ESL students.

SRAs explained that students could refuse to participate and they were instructed of their right to do so without penalty as part of the informed consent process and were provided with alternative exercises on the iPad so that neither their peers nor the SRA would know they refused to participate in the study. Our response rate was $79 / 102$ or $77 \%$ of enrolled students.

Survey participants reflected the Hostos demographic statistics reported in Table 1. Females comprised $68 \%$ of respondents, $92 \%$ were full-time students, $40 \%$ were first generation college students, $61 \%$ were between the ages 18-25, $20 \%$ were between the ages of 25 and 30, and $18 \%$ were over the age of 30 . Forty-three percent of the sample self-identified as Hispanic, 32\% as African American, and $16 \%$ as Asian American. (For institutional context, Table 3 provides a breakdown of country of origin identified by Hostos students.) Thirtynine percent of participants were enrolled in their first semester, $27 \%$ were in their second semester, and $33 \%$ had been enrolled for three or more semesters. Almost $37 \%$ were enrolled in ESL courses at the time of our study, which explains the disproportionate number of Asian students in comparison to college demographics.

Table 3

Top 10 Countries of Origin for Hostos Students

\begin{tabular}{lcc}
\hline Country of Origin & Number of Students & Percentage of Total Reported \\
\hline Dominican Republic & 3,682 & $30.53 \%$ \\
USA & 3,162 & $26.22 \%$ \\
Puerto Rico & 989 & $8.20 \%$ \\
Mexico & 495 & $4.10 \%$ \\
Jamaica & 433 & $3.59 \%$ \\
Ecuador & 370 & $3.07 \%$ \\
Ghana & 321 & $2.66 \%$ \\
Honduras & 195 & $1.62 \%$ \\
Guyana & 163 & $1.35 \%$ \\
Nigeria & 156 & $1.29 \%$ \\
\hline Notes: These are the top 10 countries that represent students who reported their country of identity in Fall 2015, \\
Spring 2016 and Summer 2016. There were 18,674 records of which 12,060 reported an identity country (not \\
missing/unknown or other) for a reporting rate of 64.6\%
\end{tabular}


Almost one-third reported being enrolled in either English or math remedial courses, or both. This proportion is much lower than the college average and may indicate a lack of understanding related to what constitutes a remedial course, particularly for ESL students, and/or perhaps participants were embarrassed to indicate they were in remedial courses (even though students were assured the information was anonymous). Twenty-nine percent indicated their primary language spoken at home was Spanish, 38\% stated English was their primary home language, and one-third indicated other. Again, the ESL students include West African and Asian students, which explains the disproportionate number of students speaking a language other than English or Spanish at home.

\section{Data Analyses}

Because our study implemented the SNS in a different population than that examined in the original scale development study, we conducted reliability analyses on both the 8-item scale and the full (13-item) SNS used in our study. Exploratory factor analyses were also conducted using both the 8-item and 13item SNS to determine if using this measure with our sample of college students would yield the same factor structure as the original study (Fagerlin et al. 2007) and demonstrate that the shorter measure has the same utility as the longer SNS.

Multivariate analyses of variance (MANOVA) were conducted to test for the main effects and interaction effects using these independent variables: gender, ethnicity, ESL course enrollment, English remedial course enrollment, and math remedial course enrollment.

\section{Results}

\section{Mean Scores and Reliability}

Table 4 presents overall means on each item for our Hostos sample alongside those reported in study 2 of Fagerlin et al. (2007). It is interesting to note that, despite the very different populations studied by us and Fagerlin et al., the results are very similar in absolute and relative terms. The one clear exception to this rule is item 12 which deals with preference for exactness in reports of the time. Setting that one outlier aside, the correlation between the means in our study and Fagerlin et al. is just short of 0.90. Moreover, the slope of the best fit line predicting their score from ours is 0.99 meaning that a one-unit increase in the score of an item in our sample corresponds to (essentially) a one-unit increase in the score of the same item in their sample.

Reliability analysis of the 13-item SNS scale was conducted using 74 cases (5 were excluded due to missing data). Item 7 was reverse coded to match the work of Fagerlin et al. (2007). In our data, Cronbach's alpha was 0.825 on the 13item scale. This analysis also showed that if item 11 was deleted, the Cronbach's 
alpha would increase to 0.836 . Additionally if item 7 was deleted, Cronbach's alpha would increase to 0.858 . These analyses demonstrate a high amount of internal consistency across items.

Table 4

Overall Means on Subjective Numeracy Scale Items

\begin{tabular}{|c|c|c|c|c|}
\hline \multirow[b]{2}{*}{ Item } & \multicolumn{2}{|c|}{$\begin{array}{c}\text { Hostos Sample } \\
n=76\end{array}$} & \multicolumn{2}{|c|}{$\begin{array}{c}\text { Fagerlin et al. (2007) Study } 2 \\
n=287\end{array}$} \\
\hline & Mean & SD & Mean & SD \\
\hline 1 & 3.82 & 1.36 & 3.67 & 1.51 \\
\hline 2 & 4.03 & 1.29 & 3.92 & 1.47 \\
\hline 3 & 4.10 & 1.45 & 4.20 & 1.54 \\
\hline 4 & 4.51 & 1.36 & $4 . .58$ & 1.40 \\
\hline 5 & 4.08 & 1.40 & 3.83 & 1.43 \\
\hline 6 & 3.66 & 1.58 & 3.53 & 1.82 \\
\hline 7 & 3.66 & 1.94 & 3.06 & 1.90 \\
\hline 8 & 4.35 & 1.24 & 4.16 & 1.50 \\
\hline $9^{*}$ & 4.43 & 1.21 & 4.05 & 1.46 \\
\hline $10^{*}$ & 3.53 & 1.44 & 3.34 & 1.42 \\
\hline $11^{*}$ & 3.19 & 1.59 & 2.92 & 1.61 \\
\hline $12^{*}$ & 4.91 & 1.71 & 2.98 & 1.90 \\
\hline $13^{*}$ & 3.86 & 1.43 & 3.45 & 1.55 \\
\hline
\end{tabular}

Reliability analysis of the 8-item SNS scale was conducted using 75 cases (4 were excluded due to missing data). One item was reverse coded (as the original developers did). Cronbach's alpha was 0.804 on the 8-item SNS scale. This analysis also showed that if item 7 was deleted, Cronbach's alpha would increase to 0.864 . The original scale development study found Cronbach's alpha to be 0.820 with the 8 -item scale (Fagerlin et al. 2007).

\section{Factor Analysis}

Factor analysis of the 13-item and 8-item SNS scales were conducted to determine if the same factors would be revealed as in the original study by Fagerlin et al. (2007). A factor analysis (maximum likelihood estimation) of the 13-item SNS scale revealed three factors that cumulatively account for $51.97 \%$ of the variance (see Table 5 for factor loadings). The chi-square goodness of fit test showed a chi-square of 62.6, $p<0.021$. The six items that loaded on Factor 1 are items 3 and 11 (calculating a tip and using percentages in conversations). The two items that highly loaded on Factor 2 are also items 3 and 11, though the latter is weighted negatively. Factor 3 was composed of these four items: items 1, 2, 3, and 11 -again a mixture of perceived ability and preferences. 
Table 5

Factor Loadings for the 13-Item Scale

\begin{tabular}{lccc}
\hline SNS Item & Factor 1 & Factor 2 & Factor 3 \\
\hline 1 & 0.001 & 0.001 & 0.348 \\
2 & 0.003 & 0.002 & 0.507 \\
3 & 0.627 & 0.816 & -0.912 \\
4 & 0.002 & 0.003 & 0.150 \\
5 & 0.000 & 0.000 & 0.154 \\
6 & 0.000 & 0.001 & 0.155 \\
7 & 0.000 & 0.001 & -0.017 \\
8 & 0.000 & 0.000 & 0.087 \\
9 & 0.001 & 0.001 & 0.106 \\
10 & 0.001 & 0.000 & 0.197 \\
11 & 0.622 & -0.829 & -0.269 \\
12 & 0.000 & 0.000 & 0.021 \\
13 & 0.001 & -0.001 & 0.026 \\
\hline
\end{tabular}

A factor analysis (maximum likelihood estimation) of the 8-item SNS scale revealed two factors that cumulatively account for $53.8 \%$ of the variance (Table $6)$. The chi-square goodness of fit test showed a chi-square of 15.6, $p<0.270$. The items which loaded on Factor 1 are items 1, 2, 3, and 4-that is, all of the ability items. Thus, Factor 1 is composed primarily of beliefs of cognitive abilities (working with fractions and percentages, calculating a tip and figuring out the cost of a shirt on sale). The four items that highly loaded on Factor 2 are: items 1, 2 , and 5. Factor 2 combines beliefs about cognitive abilities involving working with fractions and percentages and preferences for table and graphs when reading the newspaper.

Understanding and working with percentages was an important item for our students. This finding makes sense considering our sample was overrepresented with students in remedial math courses. Many such students struggle with understanding and working with percentages due to their lack of mathematical preparation coming into college.

\begin{tabular}{lcc}
$\begin{array}{l}\text { Table } 6 \\
\text { Factor Loadings for the 8-Item Scale }\end{array}$ \\
\hline SNS Item & Factor 1 & \\
\hline 1 & 0.514 & Factor 2 \\
2 & 0.725 & 0.671 \\
3 & 0.999 & 0.545 \\
4 & 0.855 & -0.005 \\
5 & 0.237 & 0.193 \\
6 & 0.427 & 0.517 \\
7 & 0.188 & 0.422 \\
8 & 0.360 & -0.145 \\
\hline
\end{tabular}

It is not possible to compare these loadings to those of Fagerlin et al. (2007) because a) those authors did not report explicit loadings and b) they only qualitatively described factor loadings for developmental versions of the SNS composed of 42 and 6 items. Nevertheless, based on what they do say, it is 
possible to make some comparative observations. In their 42-item SNS, Fagerlin et al. find 3 factors related to experience, interest, and ability. Because the ability items were most correlated with performance on their objective numeracy instrument, Fagerlin et al. kept six ability items in their reduced, 8-item instrument. They worried they had under-tested the relevance of preferences and so added 2 and 8 additional preference items to the original 2 to form the 8 - and 13-item instruments used in the present study. While they did not perform factor analysis on the resulting instruments, they seem to have constructed two factorsone related to ability and the other related to preference.

The results presented in Table 6 seem consistent with the findings of Fagerlin et al. (2007). Factor 1 clearly loads on items related to perceived cognitive ability. While Factor 2 loads a bit on preference items, we might say the same thing as Fagerlin et al. (2007, 5) do: "the ... preference items did not hang together." All in all, these patterns found among our community college respondents appear similar to those reported for those recruited from waiting areas of hospitals in the original study.

\section{Multivariate Analysis of Variance}

Multivariate analysis of variance on the data reveal main effects for ethnicity on six items (Table 7). Compared to the other ethnic groups in our sample, Hispanics and Asian Americans had higher self-ratings on their ability to work with fractions, percentages, and calculating the cost of a shirt on sale, preferred numbers when being told about the likelihood of an event happening, found exact percentages to be helpful when reading about the likelihood of an event happening, and liked statistics more than students in the other ethnic groups.

Table 7

Comparison of Mean SNS Item Responses by Ethnicity

\begin{tabular}{|c|c|c|c|c|c|c|c|c|c|c|}
\hline \multirow[b]{4}{*}{ Item } & \multicolumn{10}{|c|}{ Ethnicity } \\
\hline & \multicolumn{2}{|c|}{ Hispanic } & \multicolumn{2}{|c|}{ Black } & \multicolumn{2}{|c|}{$\begin{array}{l}\text { Asian/Pacific } \\
\text { Islander }\end{array}$} & \multicolumn{2}{|c|}{$\begin{array}{c}\text { White } \\
\text { (Non-Hispanic) }\end{array}$} & \multicolumn{2}{|c|}{ Other } \\
\hline & \multicolumn{2}{|c|}{$(n=36)$} & \multicolumn{2}{|c|}{$(n=23)$} & \multicolumn{2}{|c|}{$(n=10)$} & \multicolumn{2}{|c|}{$(n=4)$} & \multicolumn{2}{|c|}{$(n=4)$} \\
\hline & Mean & SD & Mean & SD & Mean & SD & Mean & SD & Mean & SD \\
\hline $1 *$ & 3.89 & 1.49 & 3.65 & 1.34 & 4.60 & .84 & 3.25 & .96 & 2.75 & .96 \\
\hline $2 *$ & 4.25 & 1.34 & 3.78 & 1.28 & 4.30 & .82 & 3.25 & 1.71 & 3.50 & 1.29 \\
\hline 3 & 4.03 & 1.54 & 4.09 & 1.44 & 4.70 & .68 & 3.00 & 1.41 & 4.50 & 1.91 \\
\hline $4^{*}$ & 4.58 & 1.34 & 4.35 & 1.37 & 5.00 & .82 & 3.00 & 1.41 & 5.00 & 2.00 \\
\hline 5 & 4.36 & 1.50 & 3.48 & 1.38 & 4.20 & .63 & 5.00 & .82 & 3.75 & 1.71 \\
\hline $6^{* *}$ & 4.00 & 1.31 & 3.09 & 1.81 & 4.70 & 1.06 & 2.25 & 1.50 & 2.75 & 1.50 \\
\hline 7 & 3.57 & 1.97 & 3.74 & 2.03 & 3.90 & 1.73 & 2.25 & 1.50 & 4.75 & 1.89 \\
\hline 8 & 4.28 & 1.28 & 4.35 & 1.23 & 4.50 & 1.27 & 4.00 & .82 & 5.00 & 1.41 \\
\hline $9^{* *}$ & 4.78 & .99 & 3.78 & 1.31 & 4.40 & 1.08 & 4.00 & 1.41 & 5.50 & 1.00 \\
\hline $10^{* *}$ & 3.86 & 1.50 & 3.04 & 1.55 & 4.00 & .82 & 2.25 & .50 & 3.50 & .58 \\
\hline 11 & 2.98 & 1.52 & 3.65 & 1.58 & 3.30 & 1.89 & 2.25 & .96 & 3.25 & 1.89 \\
\hline 12 & 4.97 & 1.68 & 4.74 & 1.86 & 5.10 & 1.66 & 3.75 & 1.89 & 6.00 & 0.00 \\
\hline 13 & 4.14 & 1.27 & 3.70 & 1.77 & 3.40 & 1.17 & 3.50 & 1.29 & 3.75 & 1.50 \\
\hline
\end{tabular}


Between-subjects gender effects were shown on two items (Table 8). Males had a higher mean score on all but two items. In two cases, the differences were statistically significant: males were more likely to use percentages in conversations than females and more likely than females to express an opinion using numbers.

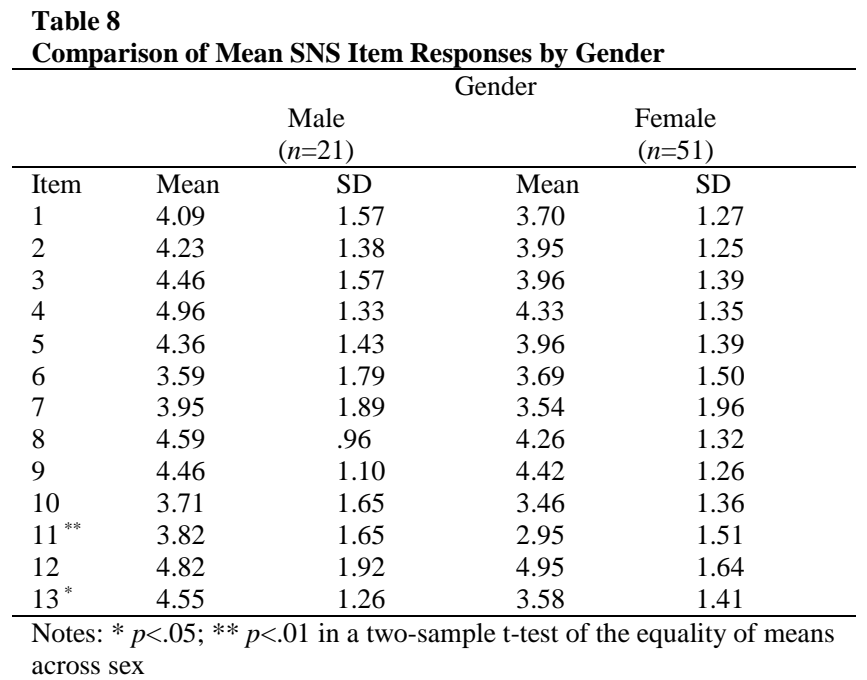

Non-ESL students had higher scores on ten of the items. Of these, a significant between-subjects effect was found on one item: students who were not currently enrolled in ESL courses found it more helpful than students enrolled in ESL courses to see exact percentages when reading about the likelihood of something happening (Table 9).

Two between-subject interaction effects were also shown. (Results are available from the authors upon request.) The first is the interaction of gender and ethnicity for item 6: Hispanic females were more likely than Hispanic males and Black/African American females to prefer numbers when being told about the chance of an event occurring. The second is a gender and ESL status interaction effect; female ESL students preferred to be told an approximate time (rather than the exact time) compared to female non-ESL students. The effect for males was reversed: male non-ESL students preferred to be told an approximate time compared to male ESL students. In fact, male ESL students were more likely to prefer an exact time than any other group. The Hispanic female preference for numbers rather words when learning about the chance of an event occurring may reflect a preference for precision rather than generalities. African American females are less likely to prefer numbers while Hispanic males are in between these two groups of females. 


\begin{tabular}{|c|c|c|c|c|}
\hline \multirow[b]{2}{*}{ Item } & \multicolumn{2}{|c|}{$\begin{array}{c}\text { ESL } \\
(n=20)\end{array}$} & \multicolumn{2}{|c|}{$\begin{array}{c}\text { Non-ESL } \\
(n=55)\end{array}$} \\
\hline & Mean & SD & Mean & SD \\
\hline 1 & 3.85 & 1.53 & 3.80 & 1.34 \\
\hline 2 & 3.95 & 1.36 & 4.09 & 1.28 \\
\hline 3 & 3.85 & 1.42 & 4.20 & 1.48 \\
\hline 4 & 4.40 & 1.27 & 4.56 & 1.42 \\
\hline 5 & 3.90 & 1.33 & 4.15 & 1.46 \\
\hline 6 & 3.35 & 1.69 & 3.73 & 1.55 \\
\hline 7 & 2.65 & 1.95 & 3.98 & 1.84 \\
\hline 8 & 4.10 & 1.55 & 4.49 & 1.09 \\
\hline $9^{*}$ & 4.05 & 1.61 & 4.62 & 0.99 \\
\hline 10 & 3.45 & 1.61 & 3.54 & 1.41 \\
\hline 11 & 3.85 & 1.63 & 3.00 & 1.54 \\
\hline 12 & 4.80 & 2.02 & 5.06 & 1.53 \\
\hline 13 & 4.10 & 1.80 & 3.80 & 1.30 \\
\hline
\end{tabular}

\section{Discussion}

The goals of our study were to assess the suitability of the SNS with predominantly minority students at a South Bronx community college and to examine the race/ethnicity, gender, and ESL enrollment effects. Our results demonstrate that the SNS is a highly reliable scale in the new context of our urban community college. Cronbach's alpha ranged from 0.804 to 0.825 on the 8 -item and 13-item scale. These reliability estimates are very similar to the ones found by the scale developers and show a high amount of internal consistency (Fagerlin et al. 2007).

Our results were also comparable in two other ways. First, when we compare our community college results to those collected in the context of hospital waiting rooms, we find the mean scores on individual items were similar in both an absolute and relative sense. This finding suggests that the two different populations are similar enough in relation to numeracy that we might use the SNS instrument in our context. Second, we find a factor structure that matches the qualitative description presented in Fagerlin et al. (2007).

Additionally, our data revealed some items that could be removed from either the 8-item and 13-item scale to increase reliability and shorten even the 8-item scale. Removal of item 7 from the shorter 8 -item scale would increase Cronbach's alpha to 0.864 resulting in a 7 -item scale. This item did not load on any of the factors in the factor analysis nor did it show any effects in the analyses of variance. It seems then that removal of item 7 would not detract from subsequent analyses and the use of a 7-item scale seems reasonable. This scale can be used in either form ( 7 or 13 items) with diverse community college students. 
These results are very encouraging. Community college students are very prone to math and test-taking anxieties. If we can use the 8-item SNS-a subjective instrument with a low cost to administer and take - we may be able to increase rapidly our understanding of students' abilities and growth in the area of numeracy.

\section{Limitations and Suggestions for Future Research}

Like Fagerlin et al. (2007), we used convenience samples to test the SNS, which poses limitations on our sample. Using a convenience sample in actual courses may have some drawbacks, such as participation being contingent on class attendance. However, with the exception of the large percentage of ESL participants, we believe our respondents are largely representative of the student population at Hostos Community College. This research could benefit greatly from a larger and more diverse student sample with more students from other disciplines and other community colleges.

We see two avenues for future research. First, while we have shown the SNS to have similar features in our sample as in the original research, we still need to determine the correlation between SNS scores and students' ability to answer numeracy problems correctly. Second, assuming the SNS is correlated with objective numeracy measures, observed differences in SNS scores across demographic groups raise questions: Are there cultural differences for numerical presentation among these ethnic groups? Could the differences across demographic groups be a reflection of our international student population? Seeking answers to these questions needs further study.

\section{Conclusion}

In summation, our results reveal that a shorter version of the SNS is highly reliable in our community college student context, has a replicable two-factor structure and that gender, race/ethnicity, and ESL are important factors in studying the beliefs and preferences of urban community college students in dealing with quantitative information. Also we have shown that the 8-item scale could be reduced to a 7-item scale while retaining high reliability in our sample. These results suggest that the SNS may be a useful, low-cost tool for assessing numeracy in the important context of community colleges.

\section{Acknowledgments}

This research was partially supported by a United States Department of Education grant that included Title $\mathrm{V}$ funds set aside for undergraduate student research. We were fortunate to have two student research assistants, Kathryn Gabriel and Grace de la Pena, during Spring 2015 who were part of our Human Research Protection 
Program (HRPP)/ IRB application and collected data and assisted with the literature review. We would also like to thank Esther Wilder for her guidance and support and to Numeracy's editorial board for working with us throughout the submission and review process.

\section{References}

Atkinson, M. P., R. F. Czaja, and Z. W. Brewster. 2006. New Study of the Literacy of College Students Finds Some Are Graduating with Only Basic Skills. Washington, DC: American Institutes for Research.

Bailey, T. 2009. "Challenge and Opportunity: Rethinking the Role and Function of Developmental Education in Community College." New Directions for Community Colleges 145: 11-30.

Dingman, S. W., and B. L. Madison. 2011. "Twenty-First-Century Quantitative Education: Beyond Content." Peer Review 13(3): 15-18.

Donnelly, P. 2005. How juries are fooled by statistics. TEDGlobal 2005.

Accessed October 92015.

http://www.ted.com/talks/peter_donnelly_shows_how_stats_fool_juries\#t336851.

Elrod, S. 2014. "Quantitative Reasoning: The Next 'Across the Curriculum' Movement." Peer Review 16(3): 4-8.

Fagerlin, A., B. J. Zikmund-Fisher, P. A. Ubel, A. Jankovic, H. A. Derry and D. M. Smith. 2007. "Measuring Numeracy without a Math Test: Development of a Subjective Numeracy Scale." Medical Decision Making 27(5): 672-80. https://doi.org/10.1177/0272989X07304449.

Gerardi, K., L. Goette, and S. Meier. 2010. "Financial Literacy and Subprime Mortgage Delinquency: Evidence from a Survey Matched to Administrative Data." Federal Reserve Bank of Atlanta Working Paper 2010-10.

"Graduation Profiles," Office of Institutional Research and Student Assessment, Office of the President, Hostos Community College. 2011. Last retrieved on Feb. 22, 2017. http://www.hostos.cuny.edu/Hostos/media/Office-of-thePresident/Institutional-Research-Assessment/HostosGraduationProfile.pdf.

Kutner, M., E. Greenburg, Y. Jin, B. Boyle, Y. Hsu, and E. Dunleavy. 2007. Literacy in Everyday Life: Results from the 2003 National Assessment of Adult Literacy. Washington, D.C.: U.S. Department of Education, National Center for Educational Statistics (NCES 2007-480).

Lipkus, I. M., G. Samsa, and B. K. Rimer. 2001. "General Performance on a Numeracy Scale among Highly Educated Samples." Medical Decision Making 21(1): 37-44. http://doi.org/10.1177/0272989X0102100105.

Lusardi, A. (2012) "Numeracy, Financial Literacy, and Financial DecisionMaking," Numeracy 5(1): Article 2. https://doi.org/10.5038/1936-4660.5.1.2. 
Madison, B. L. 2003. "The Many Faces of Quantitative Literacy.” In Quantitative Literacy: Why Numeracy Matters for Schools and Colleges, edited by B. L. Madison and L. A. Steen, 3-6. Princeton, NJ: National Council on Education and Disciplines.

Steen, L. A. 2004. "Everything I Needed to Know about Averages I Learned in College." Peer Review 6(4): 4-8.

"Student Profiles," Office of Institutional Research and Student Assessment, Office of the President, Hostos Community College. 2015. Last retrieved on Feb. 22, 2017. http://www.hostos.cuny.edu/oaa/oir/PublicDocuments/StudentProfile.pdf.

Sweet, S. and K. Strand. 2006. "Cultivating Quantitative Literacy: The Role of Sociology." Teaching Sociology 34(1): 1-4.

Vacher, H.L. and T. Chavez. 2009. "Quantitative Literacy on the Web of Science, 2-Mining the Health Numeracy Literature for Assessment Items," Numeracy 2(1): Article 5. https://doi.org/10.5038/1936-4660.2.1.5.

Wilder, E. I. 2009. "Responding to the Quantitative Literacy Gap among Student in Sociology Courses." Teaching Sociology 37(2): 151-70.

Zigmund-Fisher, B. J., D. M. Smith, P. A. Ubel, and A. Fagerlin. 2007. "Validation of the Subjective Numeracy Scale: Effects of Low Numeracy on Comprehension of Risk Communications and Utility Elicitations." Medical Decision Making 27(5): 663-71. https://doi.org/10.1177/0272989X07303824. 